\title{
Molecular interplay between microRNA-130a and PTEN in palmitic acid-mediated impaired function of endothelial progenitor cells: Effects of metformin
}

\author{
XUEMEI GU ${ }^{1 *}$, XIAO-QIAN WANG ${ }^{1 *}$, MIN-JIE LIN ${ }^{1}$, HAILI LIANG $^{1}$, SHI-YAN FAN ${ }^{1}$, \\ LUYIN WANG $^{1}$, XIAOQING YAN ${ }^{2}$, WENYUE LIU ${ }^{1}$ and FEI-XIA SHEN ${ }^{1}$ \\ ${ }^{1}$ Department of Endocrinology and Metabolism, The First Affiliated Hospital of Wenzhou Medical University; \\ ${ }^{2}$ School of Pharmaceutical Sciences of Wenzhou Medical University, Wenzhou, Zhejiang 325000, P.R. China
}

Received October 23, 2018; Accepted March 14, 2019

DOI: $10.3892 /$ ijmm.2019.4140

\begin{abstract}
Metformin serves an important role in improving the functions of endothelial progenitor cells (EPCs). MicroRNAs (miRNAs), small non-coding RNAs, have been investigated as significant regulators of EPC vascular functions. The present study investigated the molecular crosstalk between metformin and miRNA-130a (miR-130a) in the functions of EPCs exposed to palmitic acid (PA). Isolated EPCs were treated with metformin, PA, and metformin + PA, respectively. Cell Counting Kit-8, Transwell and Matrigel assays were performed to detect the proliferation, migration and tube formation ability of EPCs following different treatments. The expression of miR-130a, phosphatase and tensin homolog (PTEN) and phosphorylated-AKT was analyzed by reverse transcription-quantitative polymerase chain reaction and western blotting. The specific mechanism underlying the function of metformin in EPCs was further elucidated by transfecting miR-130a mimics and inhibitor to overexpress and inhibit the expression of miR-130a in EPCs, respectively. EPCs exhibited impaired functions of proliferation $(\mathrm{P}<0.01$ compared with the control), migration $(\mathrm{P}<0.01$ compared with the control) and tube formation $(\mathrm{P}<0.01$ compared with the control) following treatment with PA, and the expression levels of miR-130a and PTEN were decreased and increased, respectively. However, the presence of metformin, or the overexpression of miR-130a using miR-130a mimic alleviated the impairment of angiogenesis and proliferation, decreased
\end{abstract}

Correspondence to: Dr Fei-Xia Shen, Department of Endocrinology and Metabolism, The First Affiliated Hospital of Wenzhou Medical University, Building 3, Room 382, Nan Baixiang, Ouhai, Wenzhou, Zhejiang 325000, P.R. China

E-mail: shen.fx.wmu@foxmail.com

*Contributed equally

Key words: endothelial, progenitor, cell, diabetes, metformin, microRNA, phosphatase and tensin, homolog the expression of PTEN and activated the phosphoinositide-3 kinase/AKT pathway in EPCs exposed to PA. By contrast, downregulating the expression of miR-130a with a miR-130a inhibitor reversed the metformin-mediated protection. These results demonstrate the beneficial effect of miR-130a/PTEN on EPC functions, which can be regulated by metformin. The effects of metformin on improving PA-induced EPC dysfunction are mediated by miR-130a and PTEN, which may assist in the prevention and/or treatment of diabetic vascular disease.

\section{Introduction}

The incidence of type 2 diabetes mellitus (T2DM) has rapidly increased in the last decade. In China alone, the number of patients with diabetes rose from 20,400,000 in 1980 to $102,900,000$ in 2014 (1). Patients with diabetes often develop diabetic vascular complications, which are known to be associated with impaired vascular remodeling and lack of endothelial cell reconstruction function (2). Hyperlipidemia as a common comorbidity of diabetes has also been reported as an important risk factor for diabetic vascular complications (3). Palmitic acid (PA), which is one of the most common saturated free fatty acids (FFAs) found in human serum, is closely linked to the occurrence of lipotoxicity in diabetes (4). Guo et al (5) showed that PA significantly inhibited endothelial progenitor cell (EPC) proliferation and rate of migration, and their ability to form tube structures.

EPCs are a subpopulation of bone marrow mononuclear cells, which are capable of generating new blood vessels in regions of ischemia or infarction $(6,7)$. EPCs were first reported by Asahara et al (8), in 1977. It has been reported that EPCs are associated with diabetic vascular complications (9). Loomans et al (10), reported that EPCs are important regulators of impaired wound healing and reduced collateral formation in type 1 diabetes. Other studies have reported that EPCs isolated from human T2DM exhibit impaired viability, adhesion, colony formation and tube formation (11-13). Although there were several ways to improve EPC function in diabetes $(14,15)$, these are limited ways to improve the functions of EPC exposed to PA, and the underlying mechanism of this process remains to be fully elucidated. 
MicroRNAs (miRNAs) are small (20-24 nucleotides), non-coding, single-stranded RNAs that were first identified in Caenorhabditis elegans in 1993 (16,17). It is widely accepted that specific miRNAs jointly regulate different EPC functions, including proliferation, migration, tube formation, differentiation and adhesion, in addition to EPC apoptosis and autophagy (18). miR-130a has been found to be important in diabetes, as levels of miR-130a are lower than normal in the EPCs of diabetic patients; upregulation of the expression of miR-130a not only improves cell migration and colony formation but also reduces the apoptosis of EPCs in diabetic patients (19). The phosphatase and tensin homolog (PTEN) protein can affect EPC division and survival by dephosphorylating phosphoinositide-3,4,5-triphosphate to inactivate the phosphoinositide-3 kinase (PI3K)/AKT pathway $(20,21)$. A study by Song et al (22), showed that the 3'-untranslated region (3'UTR) of PTEN mRNA has an miR-130a binding site, which is involved in regulating the survival and viability of coronary artery endothelial cells. Therefore, miR-130a may serve a role in protecting EPCs from PA-induced damage via the PTEN and the PI3K/AKT pathway.

Metformin is a biguanide derivative, which is widely prescribed as an oral anti-diabetic drug for T2DM. Yu et al (23), reported that metformin can promote angiogenesis by activating the AMP-activated protein kinase (AMPK)/endothelial nitric oxide synthase pathway, which improves migration and tube formation in bone marrow-derived EPCs when these functions are impaired by high glucose levels. It was also reported that metformin attenuated diabetic retinopathy and diabetic vascular disease through combining with miRNAs $(24,25)$. However, little is known regarding the interplay between metformin and miR-130a in affecting the PA-induced impairment of EPC angiogenesis. The present study investigated the interaction between miR130a and the PTEN/PI3K/AKT pathway as a potential therapeutic target for metformin in PA-induced impaired EPC functions.

\section{Materials and methods}

Animals experiments. Animal care and all experimental protocols involving animals were approved by the Animal Care and Use Committee of Wenzhou Medical University (Wenzhou, China). A total of 50 adult male Sprague-Dawley (SD) rats (specific pathogen-free; aged 6-8 weeks (200-320 g); Wenzhou Medical University Laboratory Animal Center, Wenzhou, China) were used in the study. All rats were housed at room temperature $\left(21-25^{\circ} \mathrm{C}\right)$ with $45-50 \%$ humidity and a $12 \mathrm{~h}$ light/dark cycle, with free access to soft food and tap water.

Isolation and culture of bone marrow-derived-EPCs. The EPCs were isolated from the bone marrow of SD rats and cultured according to established methods with minor modifications $(26,27)$. Briefly, five rats per batch were sacrificed by cervical vertebra separation following anesthesia by intraperitoneal injection of $320 \mathrm{mg} / \mathrm{kg}$ chloralhydrate. Bones (femur and tibia of hind legs) from the 6-8 week-old male SD rats were repeatedly flushed with homogenate rinse solution (Tianjin Hao Yang Biological Manufacture Co. Ltd., Tianjin, China). The washing fluid was centrifuged for $10 \mathrm{~min}$ at room temperature $(700 \mathrm{x} \mathrm{g})$ and the pellet was resus- pended in $3 \mathrm{ml}$ sample diluent containing $10 \%$ fetal bovine serum (Gibco; Thermo Fisher Scientific, Inc., Waltham, MA, USA), and then was combined carefully under $3 \mathrm{ml}$ histopaque-1083 (Sigma-Aldrich; Merck KGaA, Darmstadt, Germany). Following centrifugation at $400 \mathrm{x}$ g for $30 \mathrm{~min}$ at room temperature, the mixture had separated into three layers. The cloudy layer was gently removed and washed with PBS. Following three washes, the mononuclear cells (MNCs) were resuspended in endothelial growth factor-supplemented media (EGM-2 bullet kit; Lonza Group, Ltd., Basel, Switzerland) with $10 \%$ fetal bovine serum and plated on fibronectin-coated culture plates (Sigma-Aldrich; Merck KGaA). The cells were cultured at $37^{\circ} \mathrm{C}$ with $5 \% \mathrm{CO}_{2}$ in a humidified atmosphere. The medium was replaced following the first $48 \mathrm{~h}$ and every 3 days thereafter. Late EPCs appeared after 14 days in culture, and the third or fourth passage was used for later analysis.

Characterization of bone marrow-derived-EPCs. To identify the bone marrow-derived-EPCs, immunofluorescence staining and flow cytometry were performed to analyze the expression of the specific cell markers FLK-1 and CD34. For the immunofluorescence staining, the EPCs that grew to $90 \%$ were washed with PBS three times prior to fixation with $4 \%$ paraformaldehyde. The cells were then incubated with FLK-1 (cat. no. sc-393163; Santa Cruz Biotechnology, Inc., Dallas, TX, USA; 1:400) and CD34 (cat. no. 14486-1-AP; ProteinTech Group, Inc., Chicago, IL, USA; 1:200) antibodies at $4^{\circ} \mathrm{C}$ overnight. Following incubation with the corresponding secondary antibodies at room temperature for $1 \mathrm{~h}$ (cat. no. BYE010; Boyun Biotech, Shanghai, China; 1:200) and DAPI nuclei dye, the EPCs were observed and images were captured under a fluorescence microscope (932706; Nikon Corporation, Tokyo, Japan). For flow cytometry (28), the adherent cells were digested with EDTA-free trypsin and resuspended in PBS at the density of $5 \times 10^{6}$ cells $/ \mathrm{ml}$. The MNCs were then stained with FITC-conjugated mouse anti-vascular endothelial growth factor receptor 2 (cat. no. ab184903; Abcam, Cambridge, UK; 1:200) and PE-conjugated mouse anti-CD34 (1:200; cat. no. MA1-10205; Thermo Fisher Scientific, Inc.) for $30 \mathrm{~min}$ at room temperature. The same fluorescein-labeled isotype IgG was used as a negative control for each antibody. The cells were analyzed using a flow cytometer (BD Biosciences, San Jose, CA, USA) and data were analyzed with FlowJo 7.6.1 (TreeStar, Inc., Ashland, OR, USA).

Cell proliferation. A Cell Counting Kit-8 (CCK-8) assay was used to examine cell viability. The EPCs $\left(5 \times 10^{3}\right.$ cells/well $)$ were plated on 96-well plates and cultured in EGM-2 medium supplemented with $10 \%$ FBS to induce attachment overnight. The medium was replaced with EGM-2 plus the specified additives: i) $0.5 \mathrm{mM} \mathrm{PA}$; ii) $50 \mu \mathrm{M}$ metformin, and iii) metformin + PA. Following incubation at $37^{\circ} \mathrm{C}$ with $5 \% \mathrm{CO}_{2}$ for $48 \mathrm{~h}$, the medium was aspirated and fresh DMEM without serum but containing CCK-8 (Dojindo Molecular Technologies, Inc., Kumamoto, Japan) was added (10 $\mu \mathrm{l} /$ well). Following culturing for $2 \mathrm{~h}$ at $37^{\circ} \mathrm{C}$, the absorbance was measured with a microplate reader (SpectraMax ${ }^{\circledR}$ Plus $^{384}$ Absorbance Microplate Reader; Molecular Devices, LLC, Sunnyvale, CA, USA) at a wavelength of $450 \mathrm{~nm}$. Each group had five replicates and was assessed in triplicate. 
Table I. Sequences of polymerase chain reaction primers.

\begin{tabular}{ll}
\hline Primer & \multicolumn{1}{c}{ Sequence } \\
\hline miR-130a-F & 5'-GCGCGCAGTGCAATGTTAAAAGGGCAT-3' \\
miR-132-F & 5'-ACGCGTAACAGTCTACAGCCATGGTCG-3' \\
miR-34a-F & 5'-ACGCTGGCAGTGTCTTAGCTGGTTGT-3' \\
miR-221-F & 5'-CGCGAGCTACATTGTCTGCTGGGTTTC-3' \\
U6-F & 5'-AGAGAAGATTAGCATGGCCCCTG-3' \\
PTEN-F & 5'-ATGTTCAGTGGCGGAACTTG-3' \\
PTEN-R & 5'-GTCACCACACACAGGCAATG-3' \\
GAPDH-F & 5'-GACATGCCGCCTGGAGAAAC-3' \\
GAPDH-R & 5'-AGCCCAGGATGCCCTTTAGT-3'
\end{tabular}

F, forward; R, reverse; miR, microRNA; PTEN, phosphatase and tensin homolog.

EPC migration assay. A cell migration assay was conducted in a 24-well Millicell (Corning Incorporated, Corning, NY, USA) containing a microporous $(8.0-\mathrm{mm})$ membrane. Briefly, the EPCs $\left(3 \times 10^{4}\right.$ cells/well) were resuspended in EBM-2 medium (EGM-2 bullet kit; Lonza Group, Ltd.) and added to the upper chambers. The lower chambers (24-well plates) were mixed with EGM-2 medium in the presence of metformin (50 $\mu \mathrm{M}$, Sigma-Aldrich; Merck KGaA), PA (0.5 mM, Sigma-Aldrich; Merck KGaA) or both. Following incubation for $24 \mathrm{~h}$, the non-migrated cells were removed with cotton-tipped swabs. Those cells attached to the lower chambers were fixed with $10 \%$ paraformaldehyde for $30 \mathrm{~min}$. Following DAPI staining for $30 \mathrm{~min}$, the average cell number was counted manually in random fields (magnification, x100) with an inverted microscope (Olympus CKX41; Olympus Corporation, Tokyo, Japan) in each well.

In vitro tube formation assay. The in vitro angiogenic activity of the EPCs was assessed using a Matrigel tube experiment, as described previously (24,29). In brief, Matrigel (cat. no. 356234; BD Biosciences) was thawed at $4^{\circ} \mathrm{C}$ overnight, and $150 \mu$ l Matrigel per well was added to a 48 -well plate and incubated at $37^{\circ} \mathrm{C}$ for $30 \mathrm{~min}$ to polymerize. The transfected EPCs $\left(3 \times 10^{4}\right.$ cells/well $)$ were cultured in the presence or absence of metformin, PA or their combination for $12 \mathrm{~h}$. Tube-like structures were observed under an inverted microscope (Olympus CKX41; Olympus Corporation). The numbers of tube-like structures in the images were measured using ImageJ software (National Institutes of Health, Bethesda, MD, USA). At least six random areas per well were analyzed, and the experiments were repeated three times using EPCs from three independent isolations.

miR-130a transfection. For the overexpression or inhibition of miR-130a, the EPCs were transfected with miR-130a mimics (50 nmol/1, 5'-CAGUGCAAUGUUAAAAGGGCAU-3') or inhibitor (200 nmol/1, 5'-AUGCCCUUUUAACAUUGCA CUG-3') and the corresponding negative controls (Guangzhou RiboBio Co, Ltd., Guangzhou, China) for $6 \mathrm{~h}$ using LipoFiter ${ }^{\mathrm{TM}}$ transfection reagent according to the manufacturer's protocol (Hanbio Biotechnology Shanghai Co., Ltd., Shanghai, China). Following $6 \mathrm{~h}$ of transfection, the medium was replaced with $10 \%$ FBS EGM-2 consisting of either PA or metformin for further analysis.
Prediction of miR-130a targets. The target of miR-130a was predicted by using TargetScan 7.1 (http://www.targetscan. org). Combining previous literature on miR-130a and angiogenesis $(22,30)$, PTEN was selected for further analysis as a potential target of this miRNA.

Treatment with metformin. The EPCs were cultured in EGM-2 with $10 \%$ fetal bovine serum containing either PA $(0.5 \mathrm{mM}$, Sigma-Aldrich; Merck KGaA) or metformin (50 $\mu \mathrm{M}$, Sigma-Aldrich; Merck KGaA) for $24 \mathrm{~h}$. For the miR-130a overexpression experiment, the medium was replaced with PA or metformin $6 \mathrm{~h}$ following transfection.

Reverse transcription-quantitative polymerase chain reaction $(R T-q P C R)$ analysis. Total RNA was extracted from the harvested cells using TRIzol reagent (Thermo Fisher Scientific, Inc.). To quantify the mRNA levels of PTEN, RNA was quantified and reverse transcribed into complementary DNA using specific stem-loop reverse transcription primers. The mRNA first strand synthesis was performed using a HiScript II Q RT SuperMix for qPCR (Vazyme Biotech, Co., Ltd., Piscataway, NJ, USA), and qPCR was operated using a ChamQ ${ }^{\mathrm{TM}}$ Universal SYBR qPCR Master mix (Vazyme Biotech, Co., Ltd.) on a Bio-Rad CFX96 ${ }^{\mathrm{TM}}$ R-T PCR machine (Bio-Rad Laboratories, Inc., Hercules, CA, USA). The Vazyme cycling conditions were as follows: $95^{\circ} \mathrm{C}$ for $30 \mathrm{sec}$, followed by 39 cycles at $95^{\circ} \mathrm{C}$ for $10 \mathrm{sec}$ and $60^{\circ} \mathrm{C}$ for $30 \mathrm{sec}$. A melting curve every $0.5^{\circ} \mathrm{C}$ between 65 and $95^{\circ} \mathrm{C}$ for 15 min was obtained. GAPDH was used as a loading control. To analyze the expression of miRNAs, cDNA was synthesized using the miRcute Plus miRNA First-Strand cDNA Synthesis kit (Tiangen Biotech Co., Ltd., Beijing, China) and RT-qPCR was performed using an miRcute Plus miRNA qPCR Detection kit (cat. no. FP411; Tiangen Biotech, Co., Ltd.). The Tiangen cycling conditions were as follows: $95^{\circ} \mathrm{C}$ for $15 \mathrm{~min}$, followed by 44 cycles at $94^{\circ} \mathrm{C}$ for $20 \mathrm{sec}$ and $60^{\circ} \mathrm{C}$ for $34 \mathrm{sec}$. A melting curve every $0.5^{\circ} \mathrm{C}$ between 65 and $95^{\circ} \mathrm{C}$ for 15 min was obtained. U6 was used as an internal control. The PCR primers used in the present study were synthesized by Sangon Biotech, Co., Ltd., (Shanghai, China) and the sequences are listed in Table I. The PTEN forward, 5'-ATGTTCAGT GGCGGAACTTG-3' primer and the reverse primers for miR-130a, miR-132, miR-34a, miR-221 and U6 were synthe- 
A

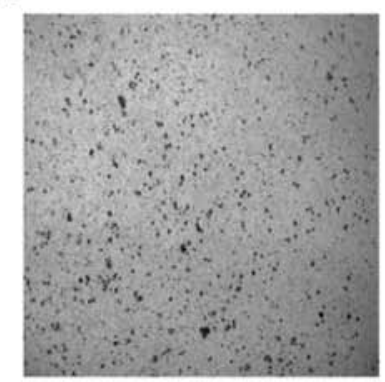

E
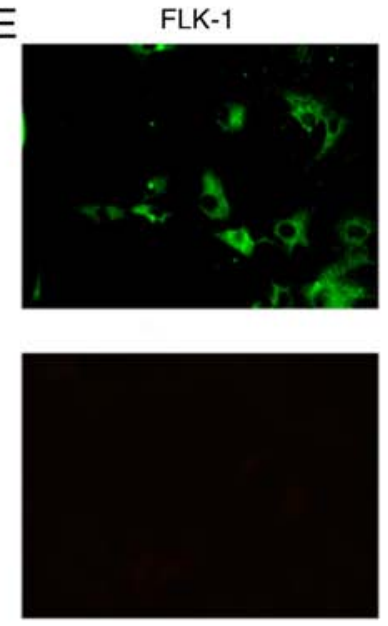

Isotype
B P0:7 days
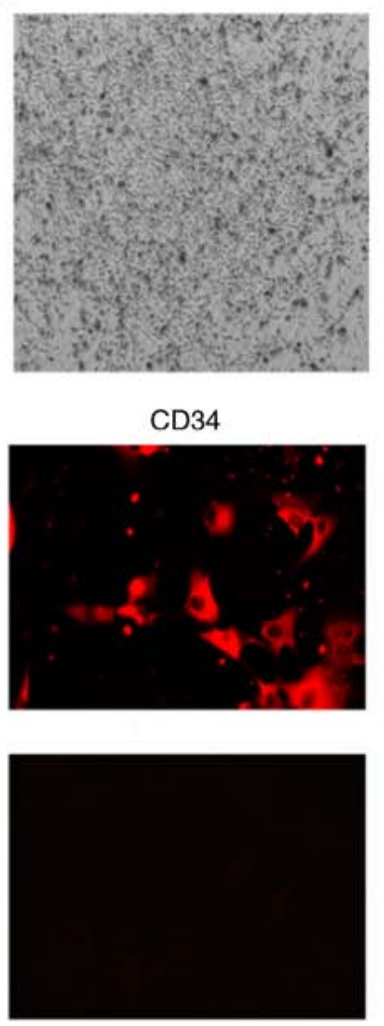

Isotype
C P0:14 days

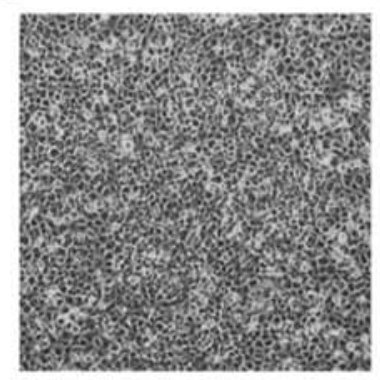

DAPI
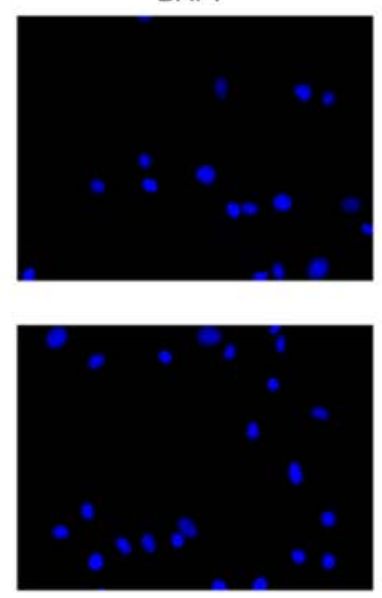

DAPI
D P1:21 days
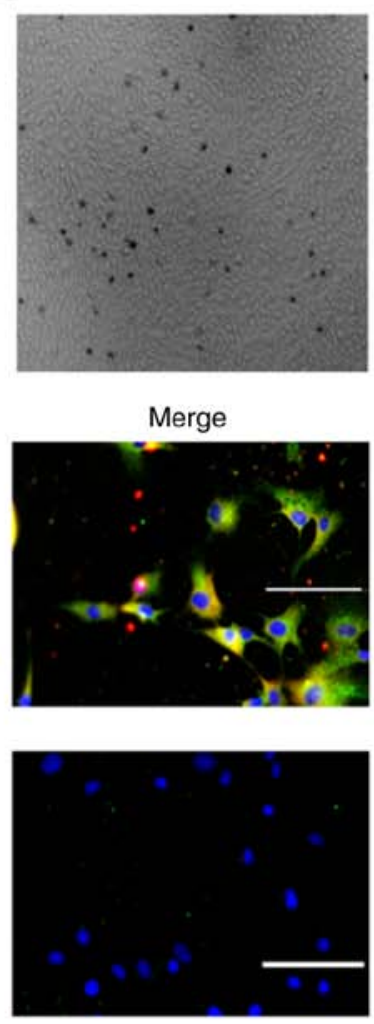

Merge
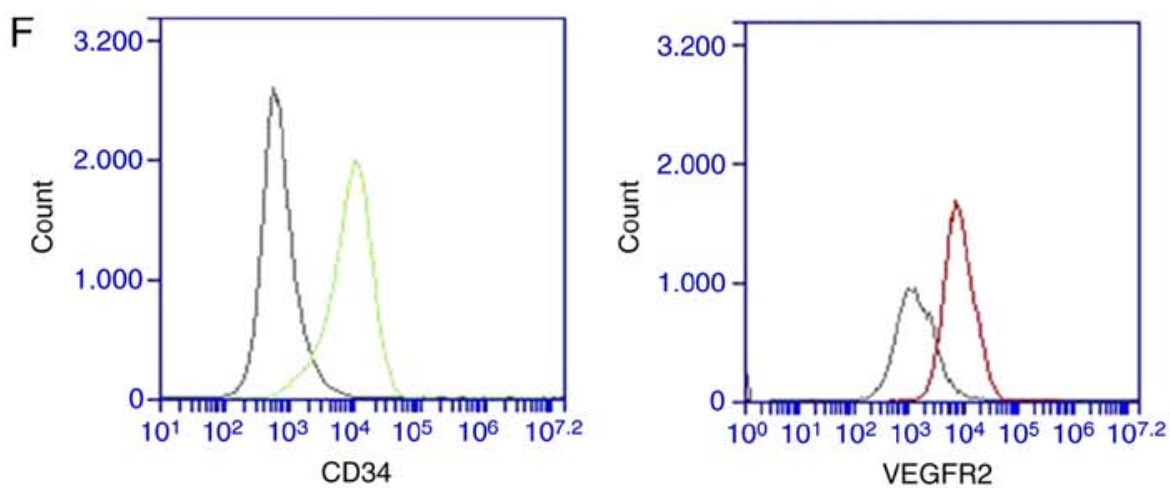

Figure 1. Characterization of bone marrow-derived EPCs. Bone marrow-derived EPCs were isolated by density gradient centrifugation and cultured in EGM-2. Images of EPCs following (A) 3 days of culture, (B) 7 days of culture and (C) 14 days of culture. (D) Stable passage of cells on day 21 of culture (Scale bar=100 $\mu \mathrm{m}$ ). (E) Immunofluorescence staining of the cell surface markers FLK-1 and CD34 (Scale bar=50 $\mu \mathrm{m}$ ). (F) Flow cytometry of cell surface markers VEGFR-2 and CD34. EPCs, endothelial progenitor cells; VEGFR-2, vascular endothelial growth factor receptor 2.

sized by Tiangen Biotech Co., Ltd., and were include in the kit applied for the synthesis of cDNA. The results were subjected to melting curve analysis and the relative gene expression levels of miRNAs were determined. The levels of PTEN genes were analyzed using the $2^{-\Delta \Delta \mathrm{Cq}}$ method (31).

Western blotting. The protein expression levels of PTEN, AKT and phosphorylated (P-)AKT were detected by western blot analysis. The EPCs were washed with pre-cooled PBS, lysed in RIPA solution, and centrifuged at $12,000 \mathrm{~g}$ for $30 \mathrm{~min}\left(4^{\circ} \mathrm{C}\right)$. Protein concentration were measured using the BCA method (Beyotime Institute of Biotechnology, Beijing, China). The proteins ( $30 \mu \mathrm{g} /$ lane) were separated on a $10 \%$ sodium dodecyl sulfate polyacrylamide gel electrophoresis and transferred onto a polyvinylidene difluoride membrane. Following blocking of the nonspecific binding sites with 5\% non-fat milk in Tris-buffered saline-Tween 20 (TBS-T), the membranes were incubated overnight with primary antibody against PTEN (1:1,000; cat. no. 9188; Cell Signaling Technology, Inc., Danvers, MA, USA), AKT (1:1,000; cat. no. 9272; Cell Signaling Technology, Inc.), and P-AKT (1:1,000; cat. no. AF0016; Affinity Biosciences, Cell Signal Transduction, Cincinnati, OH, USA) at $4^{\circ} \mathrm{C}$ overnight. The membranes were washed with TBS-T and incubated with goat anti-rabbit IgG, peroxidase-conjugated secondary antibodies (1:5,000; Biosharp Life Sciences, Hefei, China) at room temperature for $1 \mathrm{~h}$. The signals were visualized using chemiluminescence detection reagents (Pierce ECL Plus; Thermo Fisher Scientific, Inc.). The relative band intensities were determined by the Image Lab software 4.1 (Bio-Rad 

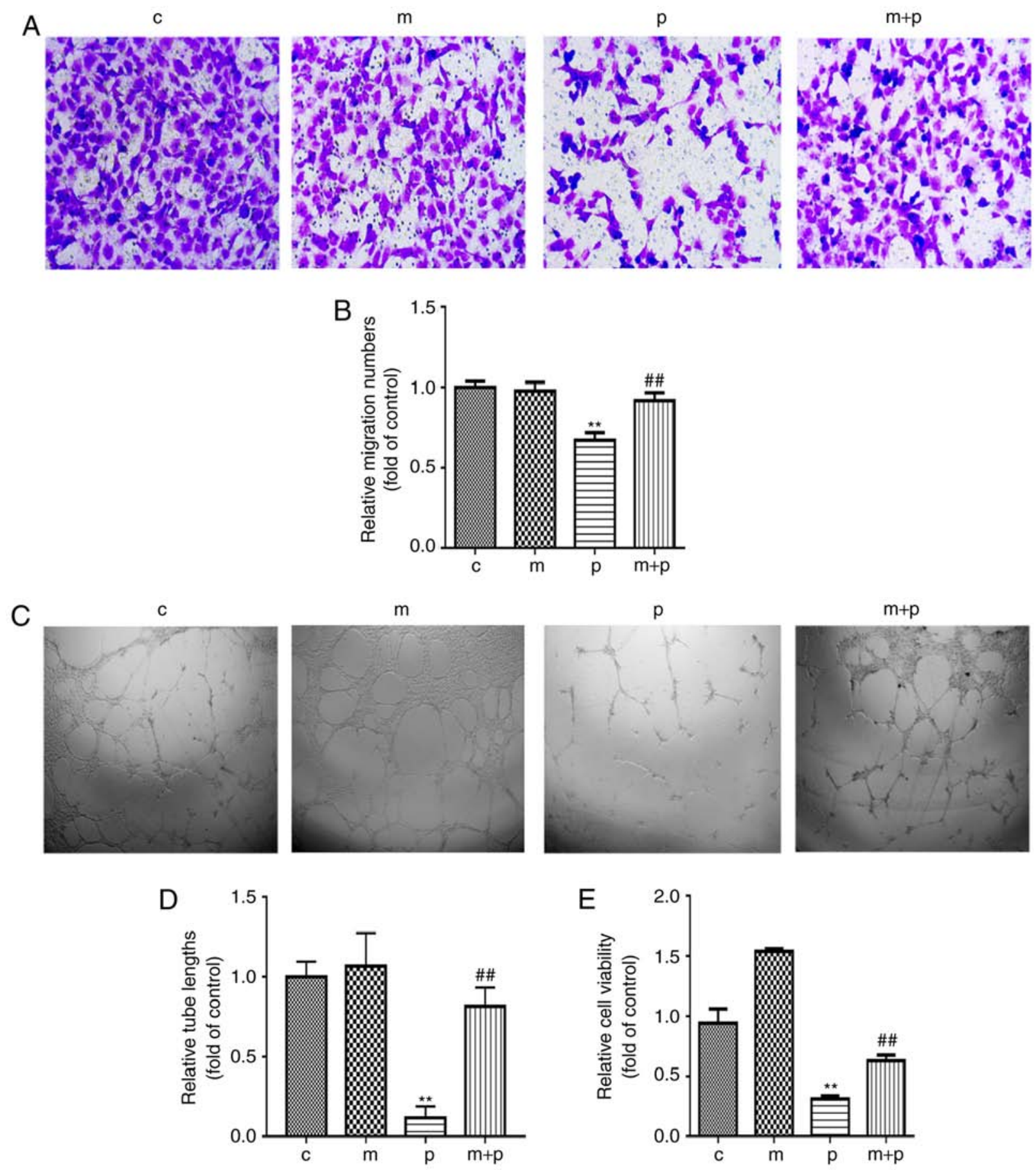

Figure 2. Metformin alleviates PA-induced injury to the proliferation and functions of bone marrow-derived EPCs. Bone marrow-derived EPCs were exposed to PA $(0.5 \mathrm{mM})$ with or without metformin $(50 \mu \mathrm{M})$ for $24 \mathrm{~h}$. (A) EPC migration was determined by a Transwell assay (magnification, $\mathrm{x} 200)$ and (B) quantified. (C) EPC tube formation was examined using a Matrigel tube experiment (magnification, x100) and (D) quantified. (E) Cell viability was investigated using a Cell Counting Kit- 8 assay. Three independent experiments were performed for each experiment. ${ }^{* *} \mathrm{P}<0.01$, vs. control; ${ }^{* \#} \mathrm{P}<0.01$, vs. PA. Data shown in the graphs represent the mean \pm standard deviation. EPCs, endothelial progenitor cells; PA, palmitic acid; C, cells treated without PA or metformin; M, cells treated with metformin; P, cells exposed to PA. M+P, cells treated with metformin and PA.

Laboratories, Inc.). GAPDH was used as an internal control. The results of the analysis were are expressed as a relative ratio of the target protein to the internal reference. All experiments were repeated three times.

Statistical analysis. All data were analyzed with the statistical software GraphPad Prism v.7.0 (GraphPad Software, Inc., San Diego, CA, USA). The statistical analysis was performed using one-way analysis of variance among groups. All contin- uous data are expressed as the mean \pm standard deviation, and $\mathrm{P}<0.05$ was considered to indicate a statistically significant difference.

\section{Results}

Characterization of bone marrow-derived EPCs. The EPCs derived from rat bone marrow were isolated by density gradient centrifugation and cultured in fibronectin-coated 

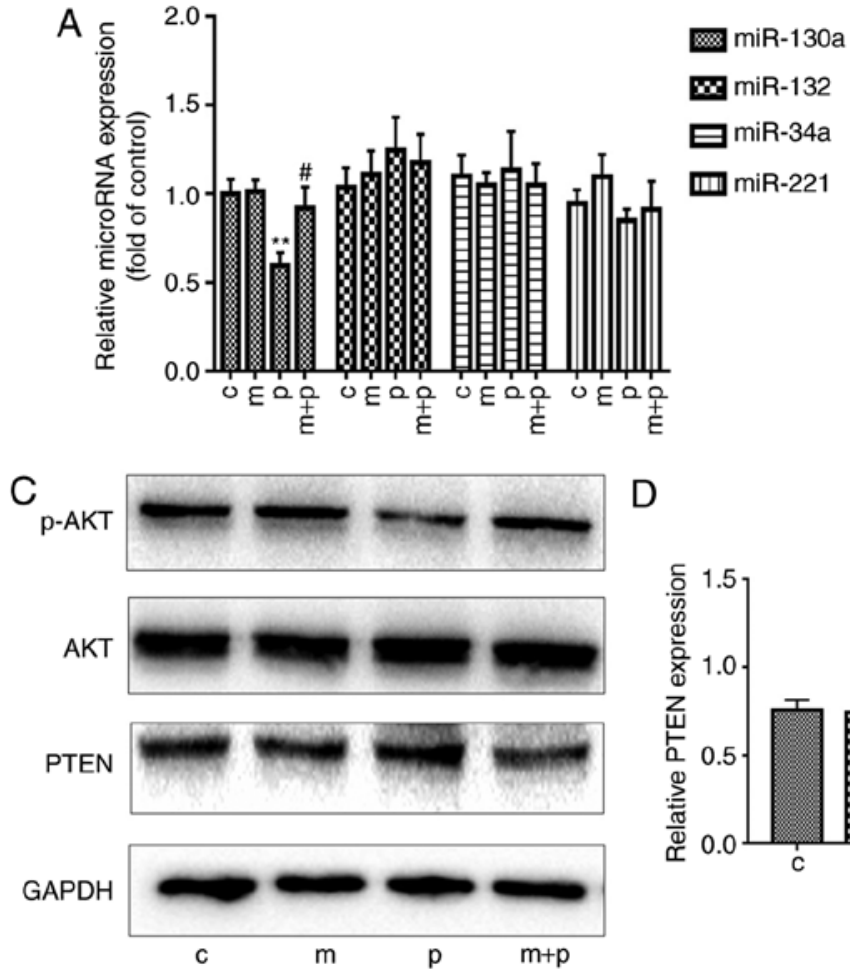

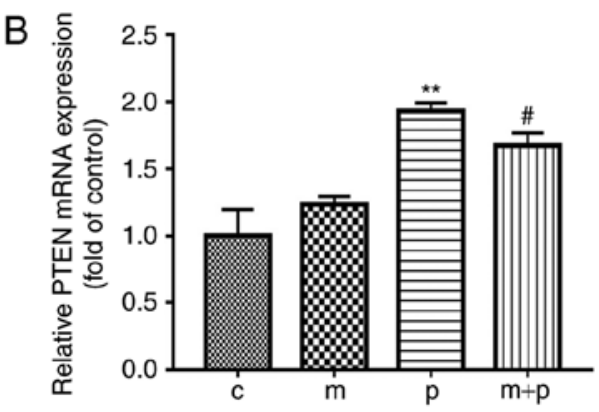

E
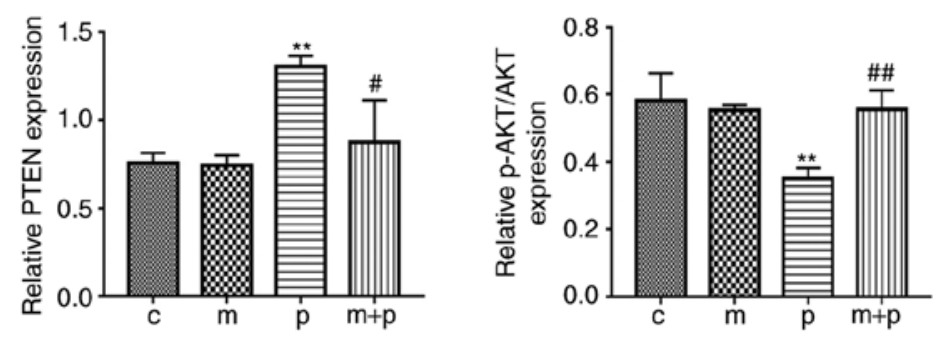

Figure 3. Metformin reverses the PA-induced reduction in expression of miR-130a and PTEN in EPCs. EPCs were cultured with metformin or 0.5 mM PA or both for $24 \mathrm{~h}$. (A) Relative expression levels of miR-130a, miR-132, miR-34a and miR-221 in EPCs were determined by RT-qPCR analysis. (B) Relative mRNA expression of PTEN was detected by RT-qPCR analysis. (C) Representative gel images and histogram values of (D) PTEN and (E) AKT and p-AKT. Three independent repeats were performed for each experiment. ${ }^{* *} \mathrm{P}<0.01$, vs. control; ${ }^{\#} \mathrm{P}<0.05$ and ${ }^{\# \#} \mathrm{P}<0.01$, vs. PA. The data shown in graphs represent the mean \pm standard deviation. miR, microRNA; EPCs, endothelial progenitor cells; PA, palmitic acid; C, cells treated without PA or metformin; M, cells treated with metformin; P, cells exposed to PA. M+P, cells treated with metformin and PA; RT-qPCR, reverse transcription-quantitative polymerase chain reaction; PTEN, phosphatase and tensin homolog; p-AKT, phosphorylated AKT.

six-well plates. Following 3 days of culture in endothelial cell growth medium EGM-2, most cells were adherent to the well surfaces (Fig. 1A); non-adherent cells were removed by replacing the medium. On day 7 of culture, the EPCs were in spindle-like cell colonies, which indicated the formation of early EPCs (Fig. 1B). Following another 7 days (on the 14th day of culture), the cell colonies gradually became larger, and the cells exhibited a cobblestone-like morphology indicating their progression into late EPCs (Fig. 1C). The first generation of late EPCs (Fig. 1D) were used for phenotypic identification and subsequent experiments. To demonstrate that these primary cells were EPCs, immunofluorescence assays and flow cytometry were performed using the first generation of EPCs. FLK-1-positive cells were stained green and CD34-positive cells were stained red. Most EPCs were positive for both FLK-1 and CD34, as shown by their yellow coloration in Fig. 1E (Merge). The flow cytometry confirmed that most of the cells were positive for CD34 and FLK-1 (Fig. 1F). This result is consistent with that of previous studies $(8,32)$.

Metformin protects EPCs from PA-induced dysfunction. To examine the function of EPCs, the cells were cultured in EGM-2 with or without PA. Transwell and Matrigel assays were used to measure the migration and angiogenic potential of the EPCs exposed to PA. As shown in Fig. 2A, the migration potential of the EPCs exposed to PA was inhibited, as the number of cells migrating to the lower chambers was significantly lower in the PA-treated EPCs than in the control cells (Fig. 2A and B). The
PA-treated EPCs also formed fewer numbers of tubes than the non-treated control EPCs (Fig. 2C and D), indicating that PA reduced the angiogenic potential of EPCs. Cell proliferation was also analyzed using CCK-8. The EPCs exposed to PA exhibited significantly lower proliferation than the control EPCs that were not exposed to PA (Fig. 2E). However, treatment of metformin eliminated the effects of PA on the EPCs (migrating ability, Fig. 2A and B; tube formation, Fig. 2C and D; proliferation, Fig. 2E). These data showed that metformin not only improved EPC proliferation (Fig. 2E), but also migration and angiogenesis (Fig. 2A-D), which indicated that metformin may prevent EPCs from PA-induced impairment.

Metformin attenuates the PA-induced reduction in expression levels of miR-130a and PTEN in EPCs. Based on an extensive literature review, four miRNAs (miR-132, miR-34a, miR-221 and miR-130a) were identified as being associated with angiogenesis $(24,33,34)$, the levels of which may be affected by EPC exposure to PA and/or metformin. In brief, the EPCs were maintained in PA $(0.5 \mathrm{mM})$ for $24 \mathrm{~h}$, following which the expression levels of the four miRNAs were measured using RT-qPCR analysis. As shown in Fig. 3A, the levels of miR-130a were significantly lower in the PA-treated EPCs than in the EPCs of the control group. It was also found that the PA-treated EPCs exhibited significantly higher mRNA and protein levels of PTEN than the control EPCs (Fig. 3B-D). However, the levels of $\mathrm{p}-\mathrm{AKT} / \mathrm{AKT}$ were significantly decreased following treatment with PA compared with the 

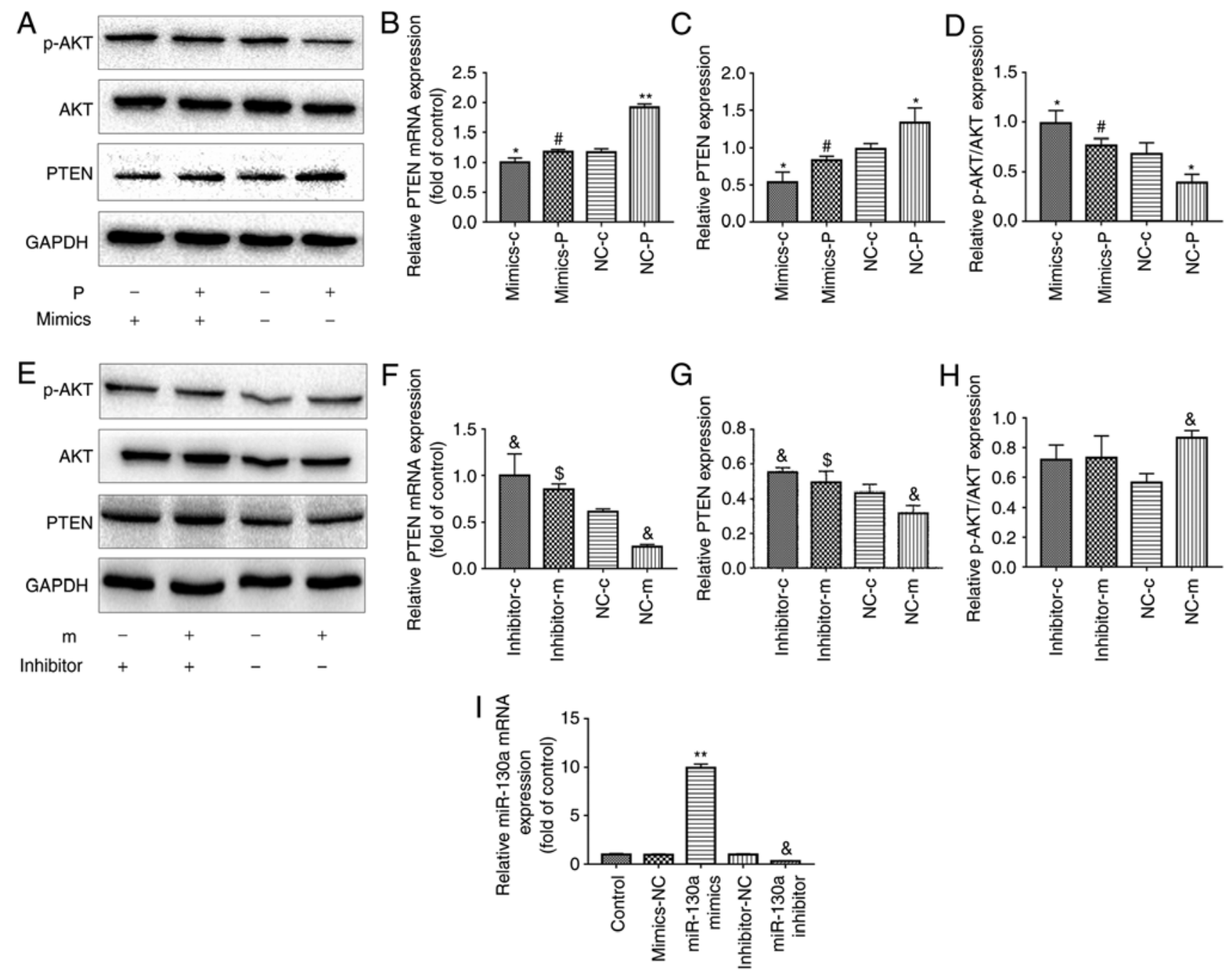

Figure 4. Metformin protection of EPC angiogenesis and proliferation from PA is associated with the regulation of miR130a, PTEN and the PI3K/AKT pathway. EPCs were transfected with either a miR-130a mimics or a miR-130a inhibitor and the corresponding NC. After 6 h, cells were exposed to media containing either PA or metformin for another $24 \mathrm{~h}$. In the mimic-treated group, (A) PTEN, AKT and P-AKT proteins were examined by western blotting, and (B) mRNA expression of PTEN was detected by RT-qPCR analysis. Protein levels of (C) PTEN and (D) P-AKT/AKT were quantified. In the inhibitor-treated group, (E) PTEN, AKT and P-AKT proteins were examined by western blotting, and (F) mRNA expression of PTEN was detected by RT-qPCR analysis. Protein levels of (G) PTEN and (H) P-AKT/AKT were quantified. ${ }^{*} \mathrm{P}<0.05$ and ${ }^{* *} \mathrm{P}<0.01$, vs. NC-c; ${ }^{"} \mathrm{P}<0.05$, vs. NC-p; ${ }^{\circledR} \mathrm{P}<0.05$, vs. NC-c; ${ }^{\$} \mathrm{P}<0.05$, vs. NC-m). (I) Relative expression of miR-130a was determined by RT-qPCR analysis. ${ }^{* *} \mathrm{P}<0.01$, vs. mimics-NC; ${ }^{\circledR} \mathrm{P}<0.05$, vs. inhibitor-NC. Three independent experiments were performed for each experiment. The data shown in the graphs represent the mean \pm standard deviation. miR, microRNA; EPCs, endothelial progenitor cells; PA, palmitic acid; C, cells treated without PA or metformin; M, cells treated with metformin; P, cells exposed to PA; mimics/inhibitor, EPCs transfected with miR-130a mimics/inhibitor; NC, EPCs transfected with the corresponding scrambled control; RT-qPCR, reverse transcription-quantitative polymerase chain reaction; PTEN, phosphatase and tensin homolog; p-AKT, phosphorylated AKT.

control (Fig. 3E). To investigate how metformin affected the expression levels of miR-130a, PTEN and p-AKT in EPCs exposed to PA, the EPCs were cultured in EGM-2-containing PA $(0.5 \mathrm{mM})$ and metformin $(50 \mu \mathrm{M})$ for $24 \mathrm{~h}$. The EPCs exposed to both metformin and PA had significantly higher levels of miR-130a and p-AKT than the EPCs exposed to PA alone (Fig. 3A and E). By contrast, the mRNA and protein expression levels of PTEN were lower in the EPCs treated with metformin and PA compared with those in the EPCs exposed to PA only (Fig. 3B-D). These data implied that metformin may attenuate the PA-induced reduction of miR-130a/p-AKT and increase of PTEN in EPCs.

miR-130a regulates the expression of PTEN in EPCs. Analyses using TargetScan softwareindicated that PTEN is a potential target of miR-130a regulation. The association between
miR-130a and PTEN was confirmed in a previous study, which showed that miR-130a specifically inhibited the expression of PTEN via a 3'UTR region in the PTEN gene (22). To confirm whether miR-130a regulates the expression levels of PTEN in EPCs, the present study investigated the mRNA and protein expression levels of PTEN in EPCs transfected with miR-130a mimics or miR-130a inhibitor. EPCs overexpressing miR-130a had significantly lower mRNA and protein levels of PTEN than those transfected with the corresponding negative control (NC) (Fig. 4A-C). By contrast, EPCs transfected with miR-130a inhibitors shown an opposite trend (Fig. 4E-G). These data indicated that miR-130a negatively regulated the expression of PTEN in EPCs.

miR-130a/PTEN and PI3K/AKT pathways are involved in the protective effects of metformin on EPCs. As mentioned above, 
A
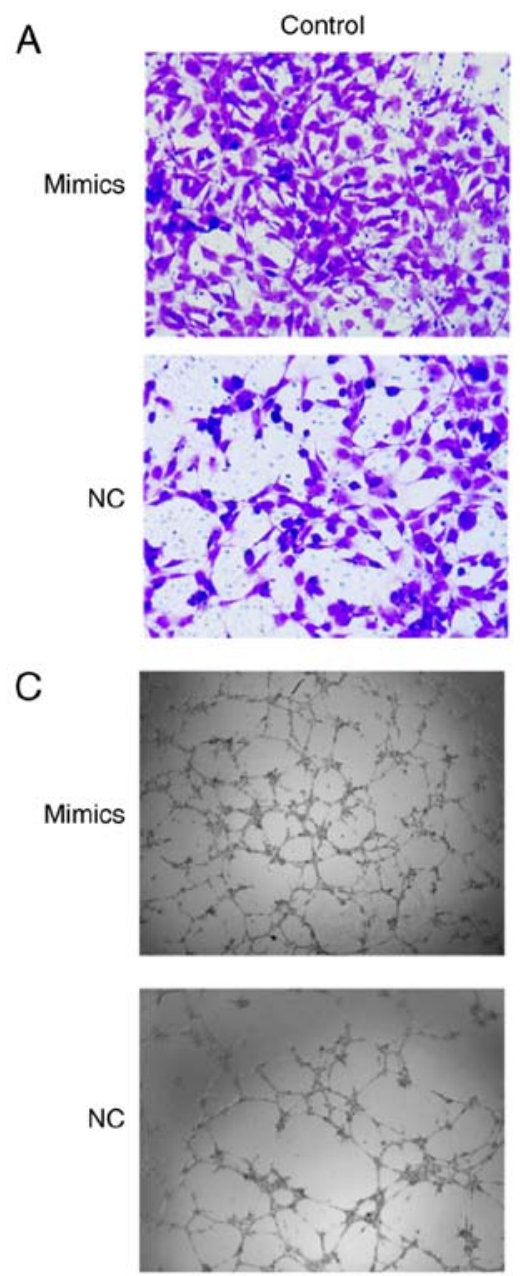
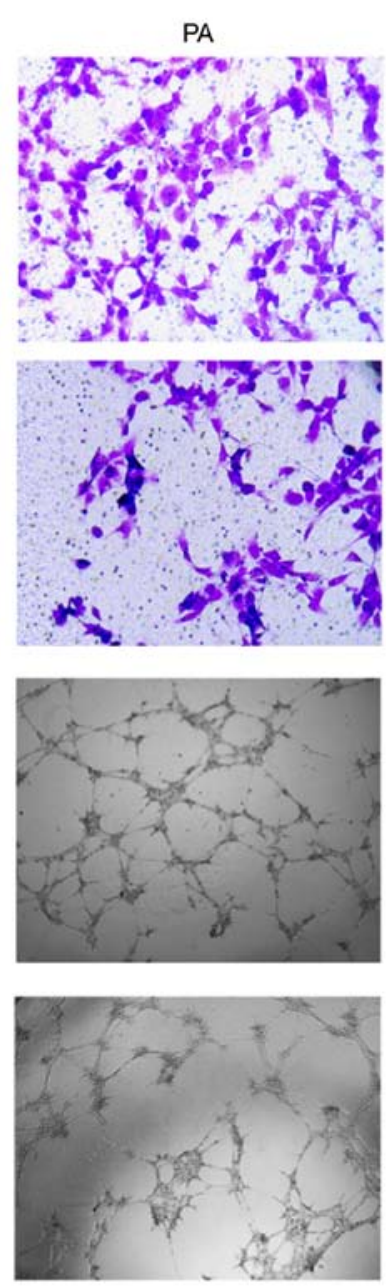

B

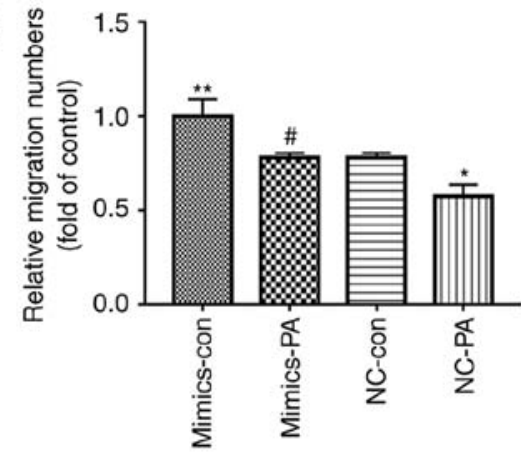

D

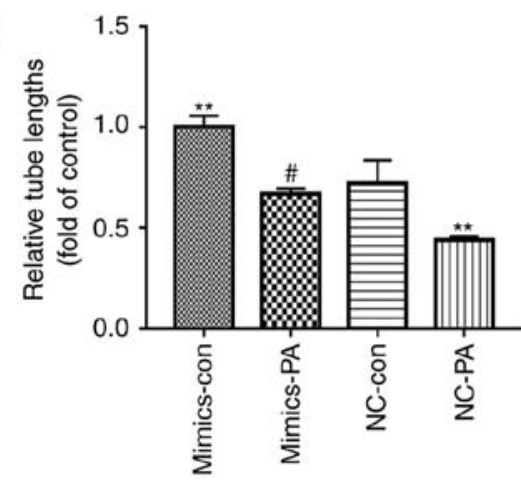

$\mathrm{E}$

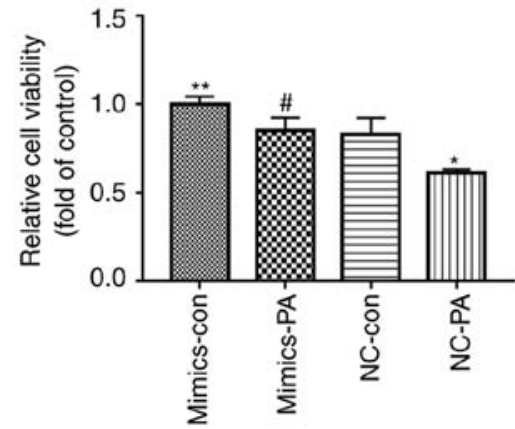

Figure 5. miR-130a is involved in the PA-induced impaired proliferation and functions of bone marrow-derived EPCs. EPCs were transfected with either scrambled control or miR-130a mimics. After $6 \mathrm{~h}$, cells were cultured with and without PA. (A) Images (magnification, x200) and (B) quantification of EPC migration ability when incubated with or without PA. (C) Images (magnification, x100) and (D) quantification of EPC tube formation when incubated with and without PA. (E) Cell viability following treatment with and without PA. Three independent experiments were performed for each experiment. "P $<0.05$ and ${ }^{* *} \mathrm{P}<0.01$, vs. NC-con; ${ }^{*} \mathrm{P}<0.05$, vs. NC-PA. The data shown in the graphs represent the mean \pm standard deviation. miR, microRNA; EPCs, endothelial progenitor cells; PA, palmitic acid; mimics, EPCs transfected with miR-130a mimics; NC, EPCs transfected with scrambled control miR-130a; con, control.

metformin improved the functions of EPCs when exposed to PA. However, whether the miR-130a/PTEN and AKT pathways were involved remained unclear. The EPCs exposed to PA or metformin were treated with miR-130a mimics or inhibitors. The increased expression of miR-130a was correlated with the activated PI3K/AKT pathway, as the p-AKT ratio was higher (Fig. 4D and I). Regarding the expression of PTEN, opposite results were observed at both the mRNA and protein levels (Fig. 4A-C). As shown in Fig. 5A-E, the impaired tube formation, migration and cell viability of the EPCs induced by PA was attenuated in the EPCs transfected with miR-130a mimics. To further investigate whether the endothelial-protective action of metformin was miR-130a-dependent, the effects of metformin in EPCs were examined following transfection with an miR-130a inhibitor. As expected, the inhibition of miR-130a in EPCs resulted in a reverse effect of metformin in the expression of PTEN (Fig. 4E-G) and miR-130a (Fig. 4I). However, no significant effects on PI3K/AKT were observed in EPCs transfected with miR-130a inhibitor (Fig. 4E and H). Similarly, the effects of metformin on angiogenesis and cell viability significantly decreased in EPCs transfected with the miR-130a inhibitor (Fig. 6A-E). In summary, the ameliorative effect of metformin on PA-induced changes in EPC proliferation, cell migration and tube formation may be associated with an increase in the expression levels of miR-130a and a decrease in the levels of PTEN, which may be associated with activation of the PI3K/AKT signaling pathway.

\section{Discussion}

EPCs are known to be involved in vascularization and angiogenesis during embryonic development and in adults (35). It has been reported that diabetes can reduce the viability and angiogenic potential of EPCs, which is a likely reason why patients with diabetes are at a high risk of developing cardiovascular problems, chronic renal failure and peripheral 
A
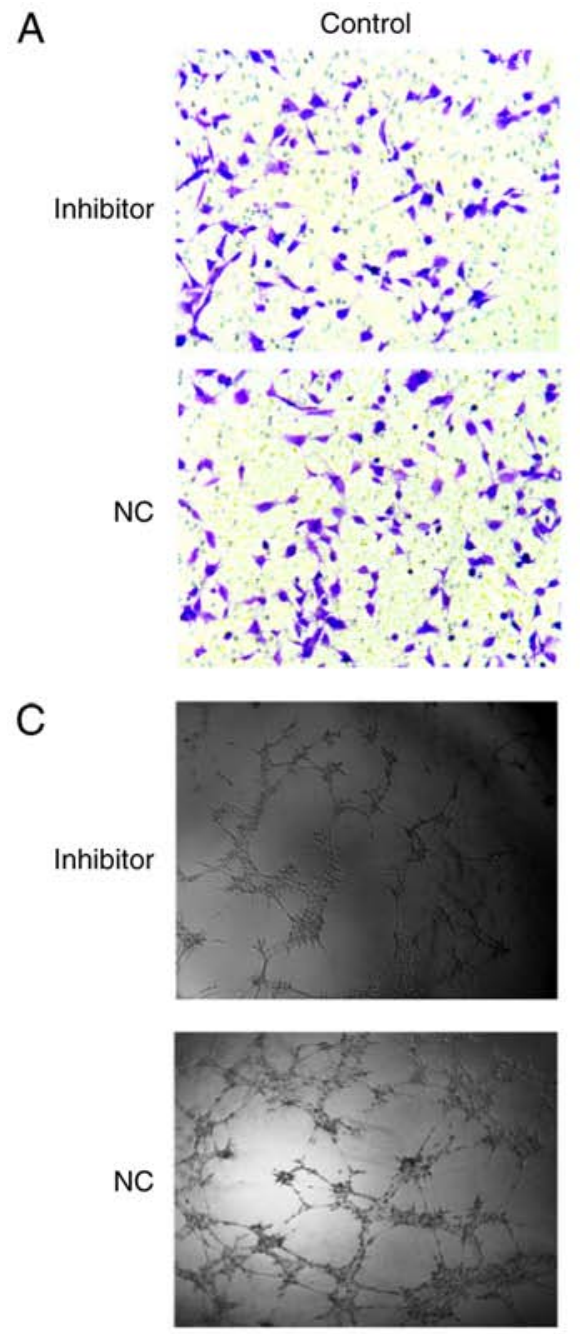
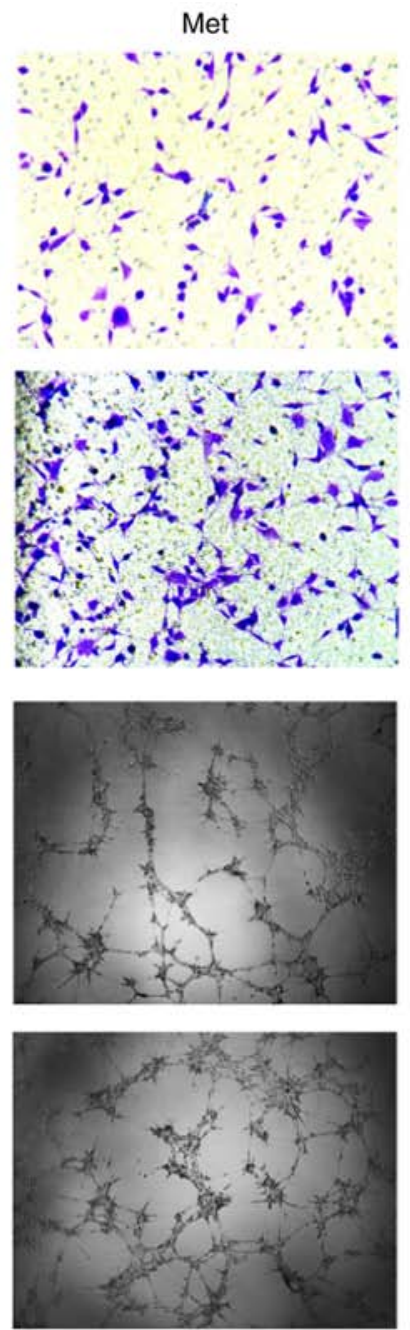

B

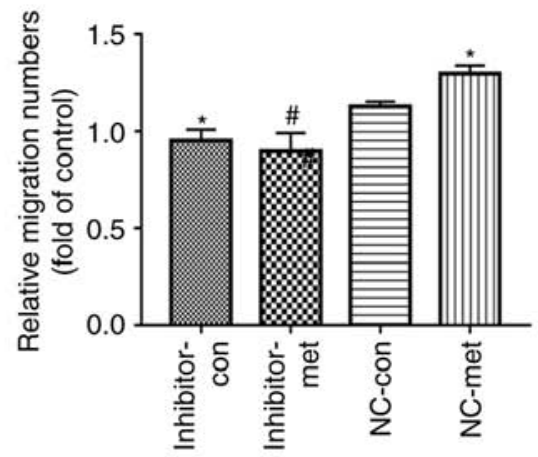

D

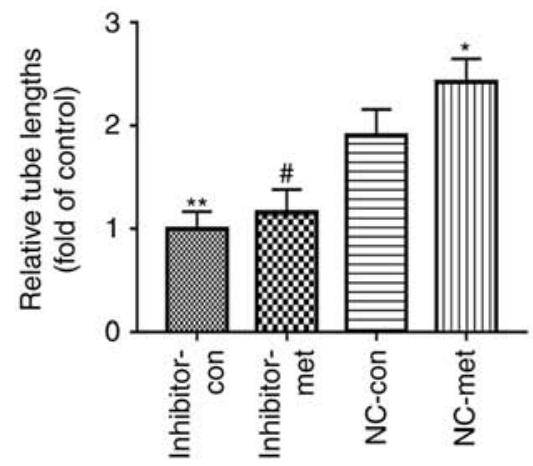

$\mathrm{E}$

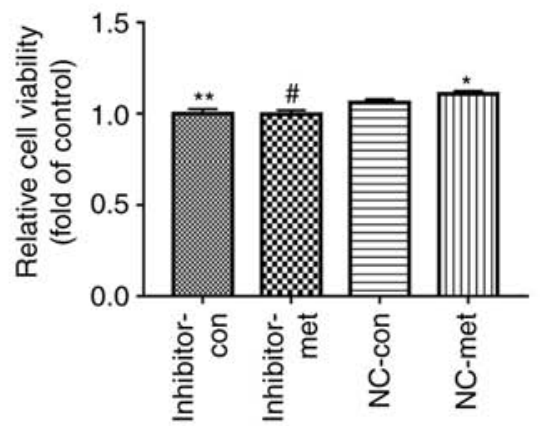

Figure 6. Downregulation of miR-130a reverses the metformin-induced EPC proliferation and angiogenesis improvement when exposed to PA. EPCs were treated with miR-130a inhibitor or NC. After $6 \mathrm{~h}$, the medium was replaced with medium or without metformin. (A) EPC migration was determined using a Transwell assay (magnification, x200). (B) Relative numbers of cells migrated. (C) Tube formation was examined by a Matrigel tube experiment (magnification, $\mathrm{x} 100$ ). (D) Relative tube lengths. (E) Cell viability was investigated using a Cell Counting Kit- 8 assay. Three independent experiments were performed for each experiment. ${ }^{*} \mathrm{P}<0.05$ and ${ }^{* *} \mathrm{P}<0.01$, vs. NC-con; ${ }^{*} \mathrm{P}<0.05$, vs. NC-met. The data shown in the graphs represent the mean \pm standard deviation. miR, microRNA; EPCs, endothelial progenitor cells; PA, inhibitor, EPCs transfected with miR-130a inhibitor; NC, EPCs transfected with miR-130a negative control; con, control; met, metformin.

vascular complications (36-38). Several studies have shown that metformin can increase the angiogenic potential of EPCs in diabetes $(23,35)$. However, whether metformin can protect the EPCs from PA-induced dysfunctions, and whether the potential mechanism involves miRNAs remain to be elucidated. In the present study, it was found that metformin improved the proliferation, migration and tube formation capacities of PA-exposed EPCs; high levels of PA were used to mimic metabolic disorders in vitro. The results demonstrated that metformin exerted its ameliorative effects via the upregulation of miR-130a and downregulation of PTEN in PA-exposed EPCs.

Diabetes is recognized as a metabolic syndrome characterized by the dysregulation of glucose, fat and protein metabolism. Song et al (39), showed that the senescence and impaired angiogenic functions of EPCs exposed to high glucose and FFAs, as observed in diabetes, were partly mediated by the sirtuin 1/P53/P21 signaling pathway. Another previous study indicated that PA partially suppressed the expression and activities of cathepsin $\mathrm{L}$ and $\mathrm{S}$, leading to reduced endothelial cell proliferation and invasion, with a concomitant increase in apoptosis (2). Furthermore, the PI3K/AKT/forkhead box O1 pathway was found to be involved in PA-induced reduction in endothelial cell angiogenesis (40). The present study showed that PA significantly decreased the proliferation, migration and tube formation of EPCs, and these effects of PA on EPCs were attenuated by treatment with metformin. The results of present study are consistent with a report by Han et al (41), which showed that metformin not only improved wound closure in $\mathrm{db} / \mathrm{db}$ mice but also increased the numbers and angiogenic potential of EPCs. However, Li et al (42) also reported that metformin inhibits endothelial progenitor cell migration by decreasing matrix metalloproteinase- 2 and -9 , via the AMPK/mammalian target of rapamycin/autophagy pathway, which differs from the findings of the present study. The different effects of metformin on EPC migration among these 
studies may be due to the different concentration of metformin used; the concentration of metformin used by Li et al (42) was $10 \mathrm{mM}$, which was substantially higher than that in the present study $(50 \mu \mathrm{M})$. High concentrations of metformin have been found to inhibit tumor growth and proliferation, and is considered to be a promising drug for treating tumors $(43,44)$, although a low concentration of metformin exerted effects on accelerating wound healing in diabetic mice and improved the functions of EPCs (23). Metformin is a widely used first-line hypoglycemic agent that affects angiogenesis in numerous medical conditions, including esophageal squamous cell cancers, retinal vascular endothelial cell cancers and hepatocellular carcinomas (45-47). Until now, the mechanism by which metformin protects EPCs from PA has remained unclear.

Several studies have found that endothelial progenitor-specific miRNAs can regulate the proliferative, migration and tube formation capacities of EPCs $(48,49)$. miR-130a, is present in numerous cells and is known to have important effects on multiple functions. Duan et al (50), showed that miR-130a can function as an oncogene to promote the proliferation and migration of gastric cells. Liang et al (51), showed that miR-130a can also protect glomerular cells from lipopolysaccharide-induced injury by activating the PI3K/AKT pathway and ameliorating inflammation. In EPCs, the expression of miR-130a was found to decrease in diabetes, which was associated with high levels of glucose and lipids (19). In the present study, the expression of miR-130a in PA-exposed EPCs was significantly lower than that in control EPCs, which was similar to the results reported by Ye et al (19), in which the expression levels miR-130a were lower than normal in the EPCs of diabetic patients. The present study also found that treating PA-exposed EPCs with metformin reversed this effect. The overexpression of miR-130a using miR-130a mimics also improved the proliferation, migration and tube formation capacities of EPCs exposed to PA. However, metformin did not effectively reverse the PA-induced dysfunction in EPCs transfected with miR-130a inhibitor. Taken together, the results indicated that miR-130a may be involved in the effects exerted by metformin on PA-exposed EPCs.

The present study demonstrated that the downregulation of miR-130a in PA-exposed EPCs led to an increased expression of PTEN, which is considered to be a major regulator of angiogenesis in endothelial cells (30). A study by Song et al (22), showed that PTEN is a target of miR-130a. PTEN is also involved in the angiogenic effects of human umbilical cord exosomes and the extracellular vesicles of lung cancer on endothelial cells $(52,53)$. Furthermore, it was also reported that the expression of PTEN was significantly higher in skeletal muscle cells with glucose-induced insulin resistance than that in normal skeletal muscle cells, and metformin significantly reduced insulin resistance by decreasing the expression levels of PTEN in these cells (54). In human keratinocyte cell lines, metformin was found to inhibit cell growth in a dose-dependent manner by inhibiting the miR-21/PTEN/AKT pathway (55). The present study showed that the increased expression levels of PTEN in PA-treated EPCs were reversed by treatment with metformin or by the overexpression of miR-130a induced by miR-130a mimics. By contrast, downregulating the expression of miR-130a with an miR-130a inhibitor reversed the decreased expression of PTEN induced by metformin. These results indicated that the mechanism by which metformin affected PA-exposed EPCs may be mediated by miR-130a and PTEN. However, Gao et al (56) demonstrated that miR-130a acted as an oncogene targeting tissue factor pathway inhibitor 2 and reduced cell growth and angiogenesis through FAK/PI3K/Rac1/mouse double minute 2 signaling in hemangiomas, which appears contrary to the results of the present study. Others reported that miR-130a promoted gastric cancer migration, invasion and proliferation by targeting the tumor suppressor gene Runt-related transcription factor 3 (57). Therefore miR-130a regulates the function of cells through several different pathways, depending on the type of tumor or cell. Therefore, further investigation of miR-130a is warranted. It is well accepted that PTEN suppresses the PI3K/AKT pathway by negatively regulating the activity of AKT, which is involved in regulating the proliferation, migration and angiogenesis of EPCs (58-61). The present study found that the overexpression of miR-130a activated the PI3K/AKT pathway, whereas EPCs with inhibited expression of miR-130a exhibited no significant changes in this pathway. miR-130a and PTEN may have principal roles in the protective effects of metformin in ameliorating PA-induced EPC dysfunction. The present study may serve as a foundation for preclinical studies using combinations of metformin with miR-130a inhibitor or mimics as therapeutic strategies to promote EPC angiogenesis in diabetes-associated vascular complications.

\section{Acknowledgements}

Not applicable.

\section{Funding}

This study was supported by the Natural Science Foundation Project of Zhejiang Province (grant no. LY16H070006).

\section{Availability of data and materials}

All data generated or analyzed during the present study are included in this published article.

\section{Authors' contributions}

XMG and XQW performed the research and drafted the manuscript. MJL, HLL, SYF, LYW and XQY were involved in performing experiments and performed the statistical analysis. WYL was contributed to the discussion of the experimental process and ideas. FXS conceived the study, and was involved in its design and coordination. All authors read and approved the final manuscript.

\section{Ethics approval and consent to participate}

The present study was approved by the Independent Ethics Committee of Wenzhou Medical University.

\section{Patient consent for publication}

Not applicable. 


\section{Competing interests}

The authors declare that they have no competing interests.

\section{References}

1. NCD Risk Factor Collaboration (NCD-RisC): Worldwide trends in diabetes since 1980: A pooled analysis of 751 population-based studies with 4.4 million participants. Lancet 387: 1513-1530, 2016.

2. Zhang J, Shan Y, Li Y, Luo X and Shi H: Palmitate impairs angiogenesis via suppression of cathepsin activity. Mol Med Rep 15: 3644-3650, 2017

3. Farmer JA: Diabetic dyslipidemia and atherosclerosis: Evidence from clinical trials. Curr Diab Rep 8: 71-77, 2008.

4. Listenberger LL, Han X, Lewis SE, Cases S, Farese RV Jr, Ory DS and Schaffer JE: Triglyceride accumulation protects against fatty acid-induced lipotoxicity. Proc Natl Acad Sci USA 100: 3077-3082, 2003.

5. Guo WX, Yang QD, Liu YH, Xie XY, Wang M and Niu RC: Palmitic and linoleic acids impair endothelial progenitor cells by inhibition of Akt/eNOS pathway. Arch Med Res 39: 434-442, 2008.

6. Devanesan AJ, Laughlan KA, Girn HRS and HomerVanniasinkam S: Endothelial progenitor cells as a therapeutic option in peripheral arterial disease. Eur J Vasc Endovasc Surg 38: 475-481, 2009.

7. Asahara T, Masuda H, Takahashi T, Kalka C, Pastore C, Silver M, Kearne M, Magner M and Isner JM: Bone marrow origin of endothelial progenitor cells responsible for postnatal vasculogenesis in physiological and pathological neovascularization. Circ Res 85: 221-228, 1999.

8. Asahara T, Murohara T, Sullivan A, Silver M, van der Zee R, Li T, Witzenbichler B, Schatteman G and Isner JM: Isolation of putative progenitor endothelial cells for angiogenesis. Science 275: 964-967, 1997.

9. Egan CG, Lavery R, Caporali F, Fondelli C, Laghi-Pasini F, Dotta $\mathrm{F}$ and Sorrentino V: Generalised reduction of putative endothelial progenitors and CXCR4-positive peripheral blood cells in type 2 diabetes. Diabetologia 51: 1296-1305, 2008.

10. Loomans CJ, de Koning EJ, Staal FJ, Rookmaaker MB, Verseyden C, de Boer HC, Verhaar MC, Braam B, Rabelink TJ and van Zonneveld AJ: Endothelial progenitor cell dysfunction: A novel concept in the pathogenesis of vascular complications of type 1 diabetes. Diabetes 53: 195-199, 2004.

11. Tepper OM, Galiano RD, Capla JM, Kalka C, Gagne PJ, Jacobowitz GR, Levine JP and Gurtner GC: Human endothelial progenitor cells from type II diabetics exhibit impaired proliferation, adhesion, and incorporation into vascular structures. Circulation 106: 2781-2786, 2002.

12. Barthelmes D, Irhimeh MR, Gillies MC, Karimipour M, Zhou M, Zhu L and Shen WY: Diabetes impairs mobilization of mouse bone marrow-derived Lin(-)/VEGF-R2(+) progenitor cells. Blood Cells Mol Dis 51: 163-173, 2013.

13. Trombetta A, Togliatto G, Rosso A, Dentelli P, Olgasi C, Cotogni $\mathrm{P}$ and Brizzi MF: Increase of palmitic acid concentration impairs endothelial progenitor cell and bone marrow-derived progenitor cell bioavailability: Role of the STAT5/PPARgamma transcriptional complex. Diabetes 62: 1245-1257, 2013.

14. Badr G, Hozzein WN, Badr BM, Al Ghamdi A, Saad Eldien HM and Garraud O: Bee venom accelerates wound healing in diabetic mice by suppressing activating transcription factor-3 (ATF-3) and inducible nitric oxide synthase (iNOS)-mediated oxidative stress and recruiting bone marrow-derived endothelial progenitor cells. J Cell Physiol 231: 2159-2171, 2016.

15. Abplanalp WT, Conklin DJ, Cantor JM, Ginsberg $\mathrm{MH}$, Wysoczynski M, Bhatnagar A and O'Toole TE: Enhanced integrin $\alpha 4 \beta 1$-mediated adhesion contributes to a mobilization defect of endothelial progenitor cells in diabetes. Diabetes 65: 3505-3515, 2016.

16. Lee RC, Feinbaum RL and Ambros V: The C. elegans heterochronic gene lin-4 encodes small RNAs with antisense complementarity to lin-14. Cell 75: 843-854, 1993.

17. Bartel DP: MicroRNAs: Genomics, biogenesis, mechanism, and function. Cell 116: 281-297, 2004.

18. Qu K, Wang Z, Lin XL, Zhang K, He XL and Zhang $\mathrm{H}$ : MicroRNAs: Key regulators of endothelial progenitor cell functions. Clin Chim Acta 448: 65-73, 2015.
19. Ye M, Li D, Yang J, Xie J, Yu F, Ma Y, Zhu X, Zhao J and Lv Z: MicroRNA-130a targets MAP3K12 to modulate diabetic endothelial progenitor cell function. Cell Physiol Biochem 36: 712-726, 2015.

20. Song MS, Carracedo A, Salmena L, Song SJ, Egia A, Malumbres M and Pandolfi PP: Nuclear PTEN regulates the APC-CDH1 tumor-suppressive complex in a phosphatase-independent manner. Cell 144: 187-199, 2011.

21. Shiojima I and Walsh K: Role of Akt signaling in vascular homeostasis and angiogenesis. Circ Res 90: 1243-1250, 2002

22. Song CL, Liu B, Shi YF, Liu N, Yan YY, Zhang JC, Xue X, Wang JP, Zhao Z, Liu JG, et al: MicroRNA-130a alleviates human coronary artery endothelial cell injury and inflammatory responses by targeting PTEN via activating PI3K/Akt/eNOS signaling pathway. Oncotarget 7: 71922-71936, 2016

23. Yu JW, Deng YP, Han X, Ren GF, Cai J and Jiang GJ: Metformin improves the angiogenic functions of endothelial progenitor cells via activating AMPK/eNOS pathway in diabetic mice. Cardiovasc Diabetol 15: 88, 2016.

24. Arunachalam G, Lakshmanan AP, Samuel SM, Triggle CR and Ding H: Molecular interplay between microRNA-34a and Sirtuin 1 in hyperglycemia-mediated impaired angiogenesis in endothelial cells: Effects of metformin. J Pharmacol Exp Ther 356: 314-323, 2016.

25. Zhang Y, Chen F and Wang L: Metformin inhibits development of diabetic retinopathy through microRNA-497a-5p. Am J Transl Res 9: 5558-5566, 2017.

26. Dai X, Tan Y, Cai S, Xiong X, Wang L, Ye Q, Yan X, Ma K and Cai L: The role of CXCR7 on the adhesion, proliferation and angiogenesis of endothelial progenitor cells. J Cell Mol Med 15: 1299-1309, 2011

27. Brandl A, Yuan Q, Boos AM, Beier JP, Arkudas A, Kneser U, Horch RE and Bleiziffer O: A novel early precursor cell population from rat bone marrow promotes angiogenesis in vitro. BMC Cell Biol 15: 12, 2014.

28. Dai X, Yan X, Zeng J, Chen J, Wang Y, Chen J, Li Y, Barati MT, Wintergerst KA, Pan K, et al: Elevating CXCR7 improves angiogenic function of EPCs via Akt/GSK-3beta/Fyn-mediated Nrf2 activation in diabetic limb ischemia. Circ Res 120: e7-e23, 2017.

29. Yan X, Cai S, Xiong X, Sun W, Dai X, Chen S, Ye Q, Song Z, Jiang Q and Xu Z: Chemokine receptor CXCR7 mediates human endothelial progenitor cells survival, angiogenesis, but not proliferation. J Cell Biochem 113: 1437-1446, 2012.

30. Unseld M, Chilla A, Pausz C, Mawas R, Breuss J, Zielinski C, Schabbauer G and Prager GW: PTEN expression in endothelial cells is down-regulated by uPAR to promote angiogenesis. Thromb Haemost 114: 379-389, 2015.

31. Livak KJ and Schmittgen TD: Analysis of relative gene expression data using real-time quantitative PCR and the 2(-Delta Delta C(T)) method. Methods 25: 402-408, 2001.

32. Yu S, Li Z, Zhang W, Du Z, Liu K, Yang D and Gong S: Isolation and characterization of endothelial colony-forming cells from mononuclear cells of rat bone marrow. Exp Cell Res 370: 116-126, 2018.

33. Zhang X, Mao H, Chen JY, Wen S, Li D, Ye M and Lv Z: Increased expression of microRNA-221 inhibits PAK1 in endothelial progenitor cells and impairs its function via c-Raf/MEK/ERK pathway. Biochem Biophys Res Commun 431: 404-408, 2013.

34. Che F, Du H, Zhang W, Cheng Z and Tong Y: MicroRNA-132 modifies angiogenesis in patients with ischemic cerebrovascular disease by suppressing the NFkappaB and VEGF pathway. Mol Med Rep 17: 2724-2730, 2018.

35. Ambasta RK, Kohli H and Kumar P: Multiple therapeutic effect of endothelial progenitor cell regulated by drugs in diabetes and diabetes related disorder. J Transl Med 15: 185, 2017.

36. Fadini GP, Miorin M, Facco M, Bonamico S, Baesso I, Grego F, Menegolo M, de Kreutzenberg SV, Tiengo A, Agostini C and Avogaro A: Circulating endothelial progenitor cells are reduced in peripheral vascular complications of type 2 diabetes mellitus. J Am Coll Cardiol 45: 1449-1457, 2005.

37. Hill JM, Zalos G, Halcox JP, Schenke WH, Waclawiw MA, Quyyumi AA and Finkel T: Circulating endothelial progenitor cells, vascular function, and cardiovascular risk. N Engl J Med 348: 593-600, 2003.

38. Choi JH, Kim KL, Huh W, Kim B, Byun J, Suh W, Sung J, Jeon ES, Oh HY and Kim DK: Decreased number and impaired angiogenic function of endothelial progenitor cells in patients with chronic renal failure. Arterioscler Thromb Vasc Biol 24: 1246-1252, 2004. 
39. Song X, Yang B, Qiu F, Jia M and Fu G: High glucose and free fatty acids induce endothelial progenitor cell senescence via PGC-1alpha/SIRT1 signaling pathway. Cell Biol Int 41: 1146-1159, 2017.

40. Ke J, Wei R, Yu F, Zhang J and Hong T: Liraglutide restores angiogenesis in palmitate-impaired human endothelial cells through PI3K/Akt-Foxo1-GTPCH1 pathway. Peptides 86: 95-101, 2016.

41. Han X, Tao Y, Deng Y, Yu J, Sun Y and Jiang G: Metformin accelerates wound healing in type 2 diabetic $\mathrm{db} / \mathrm{db}$ mice. Mol Med Rep 16: 8691-8698, 2017.

42. Li WD, Li NP, Song DD, Rong JJ, Qian AM and Li XQ: Metformin inhibits endothelial progenitor cell migration by decreasing matrix metalloproteinases, MMP-2 and MMP-9, via the AMPK/mTOR/autophagy pathway. Int J Mol Med 39: 1262-1268, 2017

43. Ashinuma H, Takiguchi Y, Kitazono S, Kitazono-Saitoh M, Kitamura A, Chiba T, Tada Y, Kurosu K, Sakaida E, Sekine I, et al: Antiproliferative action of metformin in human lung cancer cell lines. Oncol Rep 28: 8-14, 2012.

44. Kato K, Gong J, Iwama H, Kitanaka A, Tani J, Miyoshi H, Nomura K, Mimura S, Kobayashi M, Aritomo Y, et al: The antidiabetic drug metformin inhibits gastric cancer cell proliferation in vitro and in vivo. Mol Cancer Ther 11: 549-560, 2012.

45. Han J, Li Y, Liu X, Zhou T, Sun H, Edwards P, Gao H, Yu FS and Qiao X: Metformin suppresses retinal angiogenesis and inflammation in vitro and in vivo. PLoS One 13: e0193031, 2018.

46. Zhang HH, Zhang Y, Cheng YN, Gong FL, Cao ZQ, Yu LG and Guo XL: Metformin incombination with curcumin inhibits the growth, metastasis, and angiogenesis of hepatocellular carcinoma in vitro and in vivo. Mol Carcinog 57: 44-56, 2018.

47. Yang Y, Jin G, Liu H, Liu K, Zhao J, Chen X, Wang D, Bai R, Li X, Jang Y, et al: Metformin inhibits esophageal squamous cell carcinoma-induced angiogenesis by suppressing JAK/STAT3 signaling pathway. Oncotarget 8: 74673-74687, 2017.

48. Wang N, Chen C, Yang D, Liao Q, Luo H, Wang X, Zhou F, Yang X, Yang J, Zeng C and Wang WE: Mesenchymal stem cells-derived extracellular vesicles, via miR-210, improve infarcted cardiac function by promotion of angiogenesis. Biochim Biophys Acta Mol Basis Dis 1863: 2085-2092, 2017.

49. Liang L, Zhao L, Zan Y, Zhu Q, Ren J and Zhao X: MiR-93-5p enhances growth and angiogenesis capacity of HUVECs by down-regulating EPLIN. Oncotarget 8: 107033-107043, 2017.

50. Duan J, Zhang H, Qu Y, Deng T, Huang D, Liu R, Zhang L, Bai M, Zhou L, Ying G and Ba Y: Onco-miR-130 promotes cell proliferation and migration by targeting TGFbetaR2 in gastric cancer. Oncotarget 7: 44522-44533, 2016.
51. Liang H, Yang K, Xin M, Liu X, Zhao L, Liu B and Wang J: MiR-130a protects against lipopolysaccharide-induced glomerular cell injury by upregulation of klotho. Pharmazie 72: 468-474, 2017.

52. Hu Y, Rao SS, Wang ZX, Cao J, Tan YJ, Luo J, Li HM, Zhang WS, Chen CY and Xie H: Exosomes from human umbilical cord blood accelerate cutaneous wound healing through miR-21-3p-mediated promotion of angiogenesis and fibroblast function. Theranostics 8: 169-184, 2018.

53. Zheng Y, Liu L, Chen C, Ming P, Huang Q, Li C, Cao D, Xu X and Ge W: The extracellular vesicles secreted by lung cancer cells in radiation therapy promote endothelial cell angiogenesis by transferring miR-23a. PeerJ 5: e3627, 2017.

54. Wang DF, Yang HJ, Gu JQ, Cao YL, Meng X, Wang XL, Lin YC and Gao M: Suppression of phosphatase and tensin homolog protects insulin-resistant cells from apoptosis. Mol Med Rep 12: 2695-2700, 2015.

55. Deng $\mathrm{Y}$ and Ma W: Metformin inhibits hacat cell viability via the miR-21/PTEN/Akt signaling pathway. Mol Med Rep 17: 4062-4066, 2018.

56. Gao F, Wang FG, Liu RR, Xue F, Zhang J, Xu GQ, Bi JH, Meng Z and Huo R: Epigenetic silencing of miR-130a ameliorates hemangioma by targeting tissue factor pathway inhibitor 2 through FAK/PI3K/Rac1/mdm2 signaling. Int J Oncol 50: 1821-1831, 2017.

57. Jiang $\mathrm{H}, \mathrm{Yu} \mathrm{WW}$, Wang LL and Peng Y: MiR-130a acts as a potential diagnostic biomarker and promotes gastric cancer migration, invasion and proliferation by targeting RUNX3. Oncol Rep 34: 1153-1161, 2015.

58. Oudit GY, Sun H, Kerfant BG, Crackower MA, Penninger JM and Backx PH: The role of phosphoinositide-3 kinase and PTEN in cardiovascular physiology and disease. J Mol Cell Cardiol 37: 449-471, 2004.

59. Cen M, Hu P, Cai Z, Fang T, Zhang J and Lu M: TIEG1 deficiency confers enhanced myocardial protection in the infarcted heart by mediating the Pten/Akt signalling pathway. Int J Mol Med 39: 569-578, 2017.

60. Nip H, Dar AA, Saini S, Colden M, Varahram S, Chowdhary H, Yamamura S, Mitsui Y, Tanaka Y, Kato T, et al: Oncogenic microRNA-4534 regulates PTEN pathway in prostate cancer. Oncotarget 7: 68371-68384, 2016.

61. Yu L, Li Z, Dong X, Xue X, Liu Y, Xu S, Zhang J, Han J, Yang Y and Wang H: Polydatin protects diabetic heart against ischemiareperfusion injury via Notch1/Hes1-mediated activation of Pten/Akt signaling. Oxid Med Cell Longev 2018: 2750695, 2018. 